\title{
Narrar o Alzheimer brasileiro: o alerta de Bernardo Kucinski no romance $K$.
}
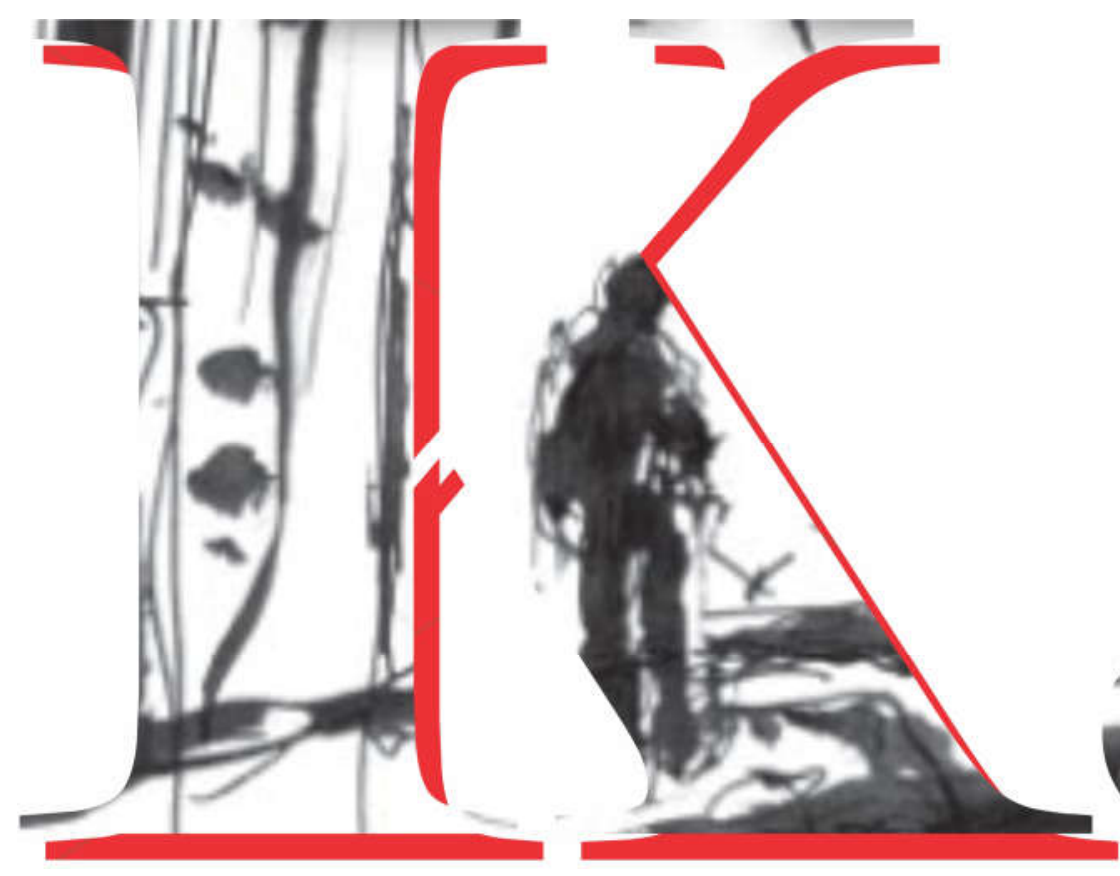

Capa do livro K., de

Bernardo Kucinski. 2011, fotografia (detalhe).

\section{Graziele Frederico}

Mestra em Literatura pela Universidade de Brasília (UnB). Doutoranda em Studi Linguistici, Letterari e Interculturali na Università degli Studi di Milano. Coorganizadora, entre outros livros, de Literatura brasileira contemporânea: resistências, escritas, leituras. Araraquara: Letraria, 2020.

graziele.frederico@gmail.com 


\section{Narrar o Alzheimer brasileiro: o alerta de Bernardo Kucinski no romance $K$.}

Narrating Brazilian Alzheimer's: the alert sent by Bernardo Kucinski in the novel $K$.

\section{Graziele Frederico}

\section{RESUMO}

No romance K. (2011), Bernardo Kucinski nomeia a ausência de políticas de memória coletiva sobre a ditadura militar brasileira como o "mal de Alzheimer nacional". As cartas que continuavam a chegar para a irmã/filha após anos de seu desaparecimento eram a materialidade desse corponação doente. Este artigo procura diagnosticar os sintomas e o combate à "doença", com base na experiência do protagonista na busca pela filha. Quais os alertas e quais as propostas de terapias possíveis apresentadas pela obra? Qual futuro pode ser lido a partir dessas memórias não compartilhadas?

PALAVRAS-CHAVE: ditadura; Alzheimer; literatura.

\section{ABSTRACT}

In the novel K. (2011), Bernardo Kucinski names the absence of collective memory policies about the Brazilian military dictatorship as the "national Alzheimer's disease". The letters that continued to arrive for Ana Rosa Kucinski (sister/daughter) after years of her disappearance were the materiality of this sick body-nation. This essay aims to "diagnose" the symptoms and the possibilities to resist, based on the protagonist's experience in the search for his daughter. What are the alerts and the possible therapies proposals? What future can be prospect in this no-sharing memories?

KEYWORDS: dictatorship; Alzheimer; literature.

A ditadura militar brasileira não teve todos seus arquivos abertos e analisados. A Comissão Nacional da Verdade ${ }^{1}$ foi vista por parte das Forças Armadas como uma afronta, conforme mais de um militar (da ativa e da reserva) declarou na época - inclusive em alguns depoimentos para a comissão - e ainda o faz. ${ }^{2}$ Mesmo assim, cinquenta anos após o golpe de 1964, o relatório final da Comissão apontou 434 vítimas identificadas em crimes urbanos, mais de 8 mil vítimas indígenas e pelo menos 20 mil torturados. Foram documentadas as graves violações de direitos humanos contra os trabalhadores urbanos, os camponeses, as igrejas, os movimentos sociais, os povos indígenas, os homossexuais, as universidades e no meio militar. Foram notificadas as inúmeras colaborações civis e econômicas com o projeto re-

\footnotetext{
${ }^{1}$ BRASIL, Comissão Nacional da Verdade, Relatório. Brasília: CNV, 2014.

${ }^{2}$ Como afirmou Eurídice Figueiredo, "o país ainda está aguardando que as Forças Armadas liberem os arquivos secretos em seu poder e façam um pedido formal de desculpas pela tortura e morte de pessoas, realizadas em dependências militares, oficiais ou clandestinas". FIGUEIREDO, Eurídice. A literatura como arquivo da ditadura brasileira. Rio de Janeiro: 7 Letras, 2017, p. 20.
} 
pressor e também as resistências a uma política sistemática de violência do Estado brasileiro.

Algumas ausências pesaram. O historiador Lucas Pedretti ${ }^{3}$, que atuou na Comissão da Verdade do estado do Rio de Janeiro, conta que os dados da violência policial nas favelas, por exemplo, não entraram na contabilização final. Os mortos executados pelos esquadrões da morte também não constam nas listagens oficiais de vítimas da ditadura. Uma estimativa divulgada pela agência de inteligência dos Estados Unidos indica que pelo menos 800 pessoas teriam sido assassinadas por esses grupos somente entre os anos de 1968 a 1971. ${ }^{4}$ Isso significa que os números que temos, mesmo que impressionantes, não podem dar conta do patrimônio traumático adquirido devido à ditadura militar.

Patrizia Violi, na obra Paesaggi della memoria ${ }^{5}$, questiona justamente como se dá o entrelaçamento de estratégias simbólicas e culturais para a construção desse patrimônio memorial e traumático: "De quem e do que somos lembrados? Por quem e por que devemos manter a memória desse passado?", são algumas das perguntas feitas por Violi ${ }^{6}$, uma vez que as escolhas determinarão tanto o conteúdo como a forma das memórias coletivas e culturais que serão construídas a partir desse patrimônio traumático. E ela complementa: “Certamente, a partir da representação mais ou menos verdadeira que damos do nosso passado, nós construímos a nossa identidade presente e sobretudo futura. A partir dessa base contamos sobre nós, nos relacionamos com os outros, produzimos, assim, cultura". ${ }^{7}$

Pensando nisso, é importante destacar que em 2020, o Instituto Brasileiro de Geografia e Estatística divulgou dados de que $54,2 \%$ da população brasileira nasceram após o ano de 1985, quando o regime militar foi oficialmente encerrado. Somando os que tinham até dez anos nesta data, o percentual sobe para $69 \%$. Isso significa que 7 em cada 10 brasileiros não viveram a ditadura ou eram muito jovens quando ela vigorava a pleno vapor. ${ }^{8}$ Voltando à Violi, para quem desejamos manter a memória das vítimas da ditadura e das opressões do regime?: "Para os seus familiares, para os sobreviventes, para as comunidades locais, para as futuras gerações, para os turistas?" 9

Diante destas perguntas, recorro a algumas reflexões de Eurídice Figueiredo ${ }^{10}$ na obra A literatura como arquivo da ditadura brasileira. Figueiredo defende o dever coletivo de memória "em relação às vítimas, a seus familiares e à sociedade em geral"11 e afirma que para ela, porém, o Estado parece se

\footnotetext{
${ }^{3}$ Ver PEDRETTI, Lucas (entrevista para Mariana Filgueiras). Contra os novos esquecimentos. In: LAUB, Michel (org.). Anuário Todavia 2018/2019. São Paulo: Todavia, 2018, p. 109.

${ }^{4}$ Cf. REINA, Eduardo e PEDRETTI, Lucas. Esquadrões mataram em 3 anos o dobro da ditadura em 21. Folha de S. Paulo, Ilustríssima, 24 out. de 2020.

${ }^{5}$ VIOLI, Patrizia. Paesaggi della memoria: Il trauma, lo spazio, la storia. Milano: Bompiani, 2014, p. 18.

${ }^{6}$ Idem, ibidem, p. 12.

${ }^{7}$ Idem, ibidem, p.18. Tradução minha do original: "Di certo, a partire dalla rappresentazione più o meno veritiera che diamo del nostro passato, noi costruiamo la nostra identità presente e soprattutto futura e su questa base ci raccontiamo, ci relazioniamo agli altri da noi, produciamo insomma cultura".

${ }^{8}$ Cf. Redação. Inspirada nas Diretas Já, Folha lança campanha em defesa da democracia. Folha de S. Paulo, 24 jun. 2020.

${ }^{9}$ VIOLI, Patrizia, op. cit., p. 12.

${ }^{10}$ Ver FIGUEIREDO, Eurídice, op. cit., p. 29.

${ }^{11}$ Idem ibidem, p. 13.
} 
recusar a "passar seu passado a limpo" e "encarar seus fantasmas". A contínua rejeição das autoridades sobre a revisão da Lei da Anistia em 1979 é uma dessas negações: “Evitar o dissenso em nome de uma unidade nacional imaginária só faz reforçar a ocultação da verdade, o que acarreta mais sofrimento para as vítimas e suas famílias, que veem a continuação da impunidade. Essa atitude apaga da memória oficial os crimes cometidos no passado e tende a ignorar as memórias divergentes que ficam assim condenadas a uma realidade marginal, clandestina". ${ }^{12}$

Recuperando Paul Ricoeur, que aproxima anistia de amnésia diante de um esquecimento que busca apagar o passado, Figueiredo afirma que no Brasil, onde "não se cultiva a memória política porque a anistia significou amnésia", "enquanto vigorar essa lei iníqua que perdoou os torturadores e os assassinos", o país "não ousará olhar para seu passado, continuará sendo um país desmemoriado, ou, como diz B. Kucisnki, um país que sofre de Alzheimer". ${ }^{13}$

É justamente sob essa perspectiva de um país doente de Alzheimer que irei analisar o romance-ensaio $K^{14}$, de Bernardo Kucinski. Nas palavras de Figueiredo, com essa obra o autor "encerra seu luto e transmite ao mesmo tempo, a imagem viva da irmã morta, uma ausente que estará presente no espírito dos leitores". ${ }^{15}$ Kucinski foi um dos primeiros autores da fase mais recente da produção literária sobre a ditadura militar brasileira (a partir de 2010). Ele publicou seu primeiro romance, K. em 2011, pela editora Expressão Popular, com enorme sucesso de crítica, sendo traduzido em treze línguas e se convertido em tema de inúmeros trabalhos acadêmicos. O romance foi também utilizado como documento na Comissão Nacional da Verdade, citado como exemplo de restituição da memória, no caso dos desaparecidos Ana Rosa Kucinski e Wilson Silva.

Bernardo Kucinski é um jornalista, intelectual e escritor que desde 1970 busca denunciar os crimes da ditadura e do autoritarismo brasileiro. Em outubro de 2018, ganhou o prêmio Especial Vladmir Herzog na $40^{a}$ premiação do Instituto Vladmir Herzog de Anistia e Direitos Humanos. Exilado político em Londres, ao sair do país em 1970 levou consigo um dos primeiros dossiês de denúncia das torturas do regime para ser publicado na imprensa inglesa. Trabalhou nos jornais alternativos de esquerda que combatiam a ditadura e introduziu a disciplina de jornalismo econômico anos mais tarde na Universidade de São Paulo, onde atuou como professor. Trabalhou na Secretaria de Imprensa do primeiro governo Lula (2003-2006) e, neste período, defendeu dentro do governo uma posição mais incisiva do Executivo para a abertura dos arquivos das Forças Armadas e uma reforma institucional que abolisse a Doutrina de Segurança Nacional que sustentava ainda os ideais do golpe de $1964 .{ }^{16}$

A obra de não ficção de Kucinski aborda questões específicas da ditadura militar, como a denúncia das torturas nas prisões brasileiras: Pau de arara:

\footnotetext{
${ }^{12}$ Idem, ibidem, p. 32.

${ }^{13}$ Idem, ibidem, p. 25 e 26.

${ }^{14}$ KUCINSKI, Bernardo. K. São Paulo: Expressão Popular, 2011.

${ }^{15}$ FIGUEIREDO, Eurídice, op. cit., p. 138.

${ }^{16}$ Sobre as posições de Kucinski no governo Lula, ver Cartas a Lula: o jornal particular do presidente e sua influência no governo do Brasil. Rio de Janeiro: Edições de Janeiro, 2014.
} 
la violence militaire au Brésil, publicado na França em 1971, Abertura: a história de uma crise (1982), e Brazil state and strugle, publicado em Londres também em 1982, assim como a análise de aspectos econômicos ligados ao regime e as suas consequências nos anos seguintes: A ditadura da dívida (1987), Fome de lucros (1987), O que são as multinacionais (1991) e Brazil carnival of the opressed (1995). Por fim, outro campo das suas publicações foi o jornalismo: duas obras exemplares são Jornalistas e revolucionários (1991) e Jornalismo econômico (1996). Sobre sua militância política e colaboração com o Partido dos Trabalhadores, Kucisnki escreveu a história do partido em Lula and the workers party in Brazil, que foi publicado em Londres no ano de 2003, além dos boletins analíticos que enviava ao candidato Luís Inácio Lula da Silva durante a campanha presidencial de 1998 - Cartas ácidas da campanha de Lula de 1998, publicado no ano 2000 - e, posteriormente, as análises feitas durante o primeiro governo do exmetalúrgico: Cartas a Lula: o jornal particular do presidente e sua influência no governo do Brasil (2014).

Na literatura, ingressou aos 74 anos, após sua aposentadoria compulsória da Universidade de São Paulo. O primeiro livro que escreveu foi uma novela policial sobre o assassinato de uma jovem professora do Instituto de Física da Universidade de São Paulo, Alice: não mais que de repente, mas que seria publicado somente em 2014. Antes disso, Kucinski lançou sua obrasímbolo e de maior sucesso, K., com primeira edição em 2011. O romance conta a busca incessante de um pai pela filha desaparecida. Com inúmeras vozes narrativas, os relatos se referem ao drama que a família do autor viveu com o sequestro e desaparecimento forçado da irmã, Ana Rosa Kucinski Silva, e o cunhado Wilson Silva em 1973, numa ação dos torturadores da ditadura militar brasileira.

Sobre a memória da repressão, Kucinski declarou em 2014 que

parece que a alma brasileira não se interessa por esse tema. O tema não lhe diz nada. Os escritores das novas gerações são portadores desse desinteresse. Ou porque se impõem problemas novos, numa era de profundas mudanças de comportamento. Na raiz disso, creio que está o fato de que a ditadura brasileira não deixou no todo da nossa sociedade um trauma para ser resolvido. A memória da ditadura é ambígua e vaga. Seu registro mais e mais vai se tornando uma imagem difusa e desimportante da nossa memória histórica. ${ }^{17}$

De acordo com Figueiredo, a literatura produzida sobre o regime realmente não envolveu substancialmente autores jovens. $\mathrm{O}$ tema ainda faz parte da produção daqueles que de alguma maneira foram afetados pela opressão militar, com algumas exceções: “Na maioria dos casos, os autores que escrevem nos dias de hoje foram afetados de maneira direta ou indireta, pela ditadura, sendo, em sua maioria pessoas nascidas nos anos 1940-1950. Nota-se, mesmo nos livros publicados entre 2010 e 2016, que poucos autores jovens abordaram a ditadura, como se ela estivesse longe demais, não fizesse parte do seu passado e não os afetasse". ${ }^{18}$

\footnotetext{
${ }^{17}$ Apud PEREIRA, Rogério. A libertação de Kucinski. Rascunho, n. 168, abr. 2014, edição 168. Disponível em $<$ http://rascunho.com.br/a-libertacao-de-kucinski/>. Acesso em 9 fev. 2021.

${ }^{18}$ FIGUEIREDO, Eurídice, op. cit., p. 42.
} 


\section{Um país com Alzheimer}

No romance K., Bernardo Kucinski lança a hipótese de que o Brasil está doente, vive um mal de Alzheimer que não permite que o país compartilhe a memória do patrimônio traumático que afetou o país a partir da violência sistêmica ditatorial. No livro há apenas dois capítulos nos quais o narrador é capturado pelo autor e dá voz a Bernardo. O primeiro - “As cartas à destinatária inexistente" é justamente o texto no qual ele exemplifica a doença da nação:

O carteiro nunca saberá que a destinatária não existe; que foi sequestrada, torturada e assassinada pela ditadura militar. Assim como o ignorarão, antes dele, o separador das cartas e todos do seu entorno. O nome no envelope selado e carimbado, como a atestar a autenticidade, será o registro tipográfico não de um lapso ou falha do computador, e sim de um mal de Alzheimer nacional. Sim, a permanência do seu nome no rol dos vivos será, paradoxalmente, produto do esquecimento coletivo do rol dos mortos. ${ }^{19}$

Ao final do capítulo, o autor-narrador sinaliza o local e data de quando enviou o livro para publicação (“São Paulo, 31 de dezembro de 2010”), demarcando no tempo e espaço a ausência/presença da irmã que desapareceu graças à ação do Estado, mas que, passadas décadas, não teve o crime completamente reconhecido pelas autoridades do país. A mensagem que o autor parece lançar é a de que não houve justiça de transição. Apesar de alguns depoimentos apurados desde a investigação da Comissão de Mortos e Desaparecidos em 1995 e, depois, na Comissão Nacional da Verdade, a família Kucinski - a exemplo de muitas outras - não teve acesso a todos os arquivos sobre a prisão, tortura e assassinato da irmã e do cunhado. Não houve julgamento dos assassinos. A memória coletiva e pública é ainda esse "mal de Alzheimer nacional".

No "Post-scriptum", texto final da obra, também na voz do autor, Bernardo Kucinski conta sobre um telefonema anônimo que o filho recebera de uma brasileira que estivera há pouco no Canadá e teria sido apresentada a uma senhora com o nome de Ana Rosa Kucinski. Para o autor-narrador, era um sinal de que os aparelhos repressivos continuam ativos, mais um dos sintomas claros da doença do país.

Não retornei o telefonema. Lembrei-me dos primeiros meses após a desaparição; sempre que chegávamos a um ponto sensível do sistema, surgiam as pistas falsas do seu paradeiro para nos cansar e desmoralizar. Esse telefonema - concluí - é uma reação à mensagem inserida nas televisões há alguns meses pela Secretaria de Direitos Humanos do governo federal, na qual uma artista de teatro personificou o seu desaparecimento. O telefonema da suposta turista brasileira veio do sistema repressivo, ainda articulado. ${ }^{20}$

A doença de Alzheimer é diagnosticada especialmente como uma decadência cognitiva, a perda da lucidez de maneira patológica. Em 1901, Alois Alzheimer recebeu a primeira paciente daquela que seria anos depois, a doen-

\footnotetext{
${ }^{19}$ KUCINSKI, Bernardo, op. cit, p. 16.
}

${ }^{20}$ Idem, ibidem, p. 177. 
ça batizada com seu nome. Auguste Deter tinha 51 anos quando foi internada na clínica para dementes e epiléticos de Frankfurt. Cinco anos depois, após ter perdido a capacidade de comunicação e mobilidade, Auguste Deter faleceria na clínica no dia 8 de abril de 1906.

Durante o tratamento, o marido informou aos médicos que sua esposa tinha sido sempre uma mulher ativa, que não bebia nada alcoólico e nem fazia uso de medicamentos. Segundo ele, ambos viviam uma união harmoniosa e feliz. A primeira mudança constatada foi o desenvolvimento de um comportamento obsessivo em cenas de ciúmes com o marido e a acusação de que ele teria saído para passear com uma vizinha. Em seguida, Auguste começou a apresentar problemas de memória de curto e longo prazo e dois meses depois já apresentava uma atitude completamente atípica para os que a conheciam. Girava pela casa com olhar perdido, sempre irrequieta e distraída, praticava enganos bobos nas suas tarefas diárias, e com o passar do tempo começou a mostrar graves problemas de decomposição cognitiva associados a afasia, apraxia, alucinações e paranoia. O marido levou-a a clínica oito meses após o início das mudanças comportamentais. Depois de alguns exames, Alzheimer descobriu que o cérebro de Auguste Deter apresentava regiões atrofiadas, mudanças arterioscleróticas, emaranhados neurofibrilares e placas neuríticas. ${ }^{21}$

O termo "doença de Alzheimer" foi cunhado por Emil Kraepelin na oitava edição do seu influente manual Psychiatric: Ein Lehrbuch fur Studierende und Artze, de 1910 como uma patologia que indicava "grave demência, profunda afasia, espasmos e crises apopléticas.

Alzheimer descreveu um singular grupo de casos com gravíssimas alterações das células. No decorrer de alguns anos, os doentes regridem mentalmente, tem uma memória fraca, são pobres de ideias, confusos, vagos, não se orientam, não reconhecem as pessoas e distribuem os próprios bens. Mais tarde, desenvolvem uma inquietude. Tornam-se frequentes os distúrbios nas atividades simbólicas e práticas; os doentes não compreendem ordens, gestos, não reconhecem objetos e imagens, não realizam ações de maneira organizada. No final, não conseguem comer sozinhos ou cuidar de si próprio. O estado final pode durar muitos anos, com uma degeneração muito lenta ou aparentemente sem grandes mudanças. ${ }^{22}$

Seguindo a metáfora proposta por Kucinski, o Brasil seria uma nação em processo de regressão, com memória fraca, escassez de ideias, confusa, vaga, desorientada, que não reconhece as pessoas e distribui seus bens. Viveríamos nesse território inquieto, onde não há uma compreensão prática, nem simbólica das ações, dos objetos e das imagens. Essa desorientação e ausência

\footnotetext{
${ }^{21}$ Cf. PASQUARELLI, Elisa. Antropologia dell'Alzheimer: neurologia e politiche della normalità. Roma: Alpes Italia, 2018, p. 27.

${ }^{22}$ Apud idem, ibidem, p. 32. Tradução minha do original: “Alzheimer ha descrito un singolare gruppo di casi con gravissime alterazioni delle cellule. Nel corso di alcuni anni i malatti regrediscono mentalmente, hanno la memoria debole, sono poveri di idee, confusi, vaghi, non si orientano, non riconoscono le persone, regalano le loro cose. Più tardi si sviluppa una certa agitazione. Sono frequenti disturbi dell'attività simbolica e pratica; i malati non comprendono ordini, gesti, non riconoscono oggetti e immagini, non compiono azioni ordinate. Molto profonde sono le logopatie. Alla fine i malati non sono in grado di mangiare da soli o di prendersi cura di sé. Lo stato finale può durare molti anni, con un deterioramento molto lento o apparentemente senza cambiamenti".
} 
de sentido permeiam todo o romance. Não há sentido em uma filha que desaparece.

No capítulo "Sorvedouro de pessoas", o narrador conta os primeiros passos desorientados do pai quando a filha não dá notícias depois de dez dias. Angustiado ele se questiona e se culpa, mudando dali em diante sua abordagem diante das atividades quotidianas, dos lugares que frequenta, dos amigos, da própria mulher. Depois que a filha desaparece, a culpa e a dúvida sobre se ele pudesse ter feito alguma coisa o consomem, enquanto a nação doente vai transportando-o para uma série de caminhos insanos, sem sentido: "Pronto, estava instalada a tragédia. O que fazer? Os dois filhos, longe, no exterior. A segunda esposa, uma inútil. As amigas da universidade em pânico. $\mathrm{O}$ velho sentiu-se esmagado. O corpo fraco, vazio, como se fosse desabar. A mente em estupor. De repente, tudo perdia sentido. Um fato único impunhase, cancelando o que dele não fosse parte; fazendo tudo o mais obsoleto" ${ }^{23}$

O desaparecimento de Ana Rosa, muda o comportamento de K. Ele começou a acusar sua segunda mulher por tê-lo distanciado da filha, pensou mal dos amigos pela sua alienação: "ele que nunca blasfemava, que tolerante aceitava as pessoas como eram, viu-se descontrolado, praguejando". Conversou com um advogado conhecido que o advertiu que se a filha tivesse sido presa por motivos políticos não havia nada que pudesse ser feito em termos legais. Mesmo assim, era prudente dar queixa do desaparecimento. Na delegacia, novamente o país doente mostrava suas instituições com distúrbios de compreensão: não iriam procurar a filha, "a polícia tinha mais o que fazer", o pai deveria esperar e, se depois de cinco dias não tivesse notícias, o delegado recomendou uma visita ao Instituto Médico Legal.

Não, os funcionários não associavam aquele rosto a nenhum dos poucos cadáveres femininos recentes, todos negros ou pardos. Quase todos, indigentes. Para dizer a verdade, deve fazer mais de um ano que não chega aqui um corpo não identificado de mulher branca. K. saiu do IML aliviado; mantinha-se a esperança de encontrá-la viva. Mas as fotografias do álbum dos indigentes e desconhecidos o deprimiram. Nem na época da guerra na Polônia deparara com rostos tão maltratados e olhos tão arregalados de pavor. ${ }^{24}$

No país que enche o instituto de corpos negros indigentes, dando cor aos rostos maltratados e olhos apavorados, outras instituições também têm suas funções capturadas. São esvaziadas de qualquer possibilidade de resposta ou proteção. O pai resolve ir até a universidade; afinal sua filha era uma professora do Instituto de Química, algum de seus superiores deveria ter notícias ou poderia fazer alguma coisa. Mas, longe dessa racionalidade lúcida, os olhos temerosos das colegas desaconselharam K. a tentar qualquer pedido na reitoria ou no departamento. Meses mais tarde, a filha seria demitida de seu cargo por abandono do emprego, em uma votação em que o narrador joga com a imaginação do que cada membro da comissão pensava para justificar o voto pela mentira do abandono quando todos sabiam que Ana Rosa "fora desaparecida".

${ }^{23}$ KUCINSKI, Bernardo, op. cit., p. 21 e 22.

${ }^{24}$ Idem, ibidem, p. 24. 
Outro dos sintomas que levam a um diagnóstico de Alzheimer, conforme a chave de leitura proposta, é a afasia, a perda do uso da linguagem, da comunicação. $\mathrm{O}$ protagonista do romance desde o início enfrentará essa saga contra a possibilidade de se expressar, de contar essa história, de não ser silenciado. É interessante o movimento proposto pelo narrador que nos mostra esse conflito tanto na comunicação com as pessoas, que nem sempre querem ouvi-lo, como em alguns casos, quando acham perigoso escutá-lo, ou, por outro lado, em uma luta interna de $\mathrm{K}$. diante da impossibilidade de narrar o trauma.

Após o sequestro da filha, um dos seus primeiros tormentos é pensar que passou tempo demais estudando e trabalhando a sua língua literária, o iídiche, e, por culpa dela, acabou isolado dos problemas do país e da vida da filha: "E como não perceber o tumulto dos novos tempos, ele, escolado em política? Quem sabe teria sido diferente se, em vez dos amigos escritores do iídiche, essa língua morta que só poucos velhos ainda falam, prestasse mais atenção ao que acontecia no país naquele momento? Quem sabe? Que importa o iídiche? Nada. Uma língua-cadáver, isso sim, que eles pranteavam nessas reuniões semanais, em vez de cuidar dos vivos". ${ }^{25}$

O pai "obcecado" tenta contar a todos a história da filha. Alguém poderia ter alguma pista. Ele passa a abordar clientes, vizinhos e até desconhecidos. Alguns o escutam e no final dizem sentir muito, outros o interrompem assim que conseguem, demonstrando que também o gesto de ouvir aquele homem que procurava por uma filha desaparecida poderia colocá-los em perigo. ${ }^{26}$ Somente um mês depois do desaparecimento é que ele fica sabendo de um grupo criado por um arcebispo católico para reunir familiares de pessoas que tinham sido sequestradas pela ditadura. Eles estavam ali em resistência à opressão do Estado que insistia em negar, em tentar silenciá-los. Buscavam alguma saída, inclusive para encontrar os corpos dos familiares que já sabiam estarem mortos: “Todos queriam falar. E queriam ouvir. Queriam entender. Talvez do conjunto de casos surgisse uma explicação, uma lógica, principalmente uma solução, uma maneira pôr fim ao pesadelo" ${ }^{27}$

Em um segundo momento, narrar essa história passa a ser uma possibilidade de impedir o segundo desaparecimento imposto à filha, o apagar da sua memória. Então, quando completa um ano das buscas, o pai começa a perseguir a possibilidade de uma lápide. A primeira tentativa foi colocar uma inscrição com o nome da filha ao lado do túmulo da esposa, no cemitério israelita. O rabino não só recusa como acha um absurdo o pedido de um sepultamento simbólico. K. argumenta que há um precedente importante: na entrada do cemitério há uma grande lápide em recordação dos mortos da Shoah. O religioso fica enfurecido pela hipótese de que a perda da filha pudesse sequer ser comparada ao genocídio judeu. Para K., não havia nenhum ataque ao mal absoluto representado pelos campos de concentração. O desaparecimento de

\footnotetext{
${ }^{25}$ Idem, ibidem, p. 19.

${ }^{26}$ Cf. idem, ibidem, p. 24.

${ }^{27}$ Idem, ibidem, p. 26.
} 
Ana Rosa era sim, para ele, a continuação do holocausto, pois “a falta da lápide equivale a dizer que ela não existiu e isso não é verdade: ela existiu, tornou-se adulta, desenvolveu uma personalidade, criou o seu mundo, formouse na universidade, casou-se. Sofre a falta dessa lápide como um desastre a mais, uma punição adicional por seu alheamento frente ao que estava acontecendo com a filha bem debaixo dos seus olhos". ${ }^{28}$

Depois do rabino acusar K. de querer homenagear uma filha terrorista e recusar-lhe a lápide, o pai imagina uma segunda hipótese: construiria um pequeno livro com fotos e a história da filha e do genro e distribuiria essa lembrança entre amigos e parentes. Já tinha visto gestos assim na sua Polônia natal e poderia de alguma forma impedir que apagassem a história de Ana Rosa e Wilson Silva. Para impressão, ele escolheu uma gráfica do bairro. Antigamente era dirigida por Ítalo, um italiano anarquista com quem algumas vezes $K$. tinha trocado ironias políticas. Quando voltou para saber os custos da impressão, o velho polonês foi recebido aos gritos pelo novo dono da gráfica, o filho de Ítalo. Ofendido pelo material "subversivo" que K. tinha trazido, o jovem expulsou o antigo vizinho e ainda indignado perguntou se o pai não sabia que a filha era uma comunista. ${ }^{29}$

Outra possibilidade aventada por $\mathrm{K}$. foi resistir à afasia infringida pela nação, "sorvedouro de pessoas", através da literatura. Desde que participou do primeiro encontro com o grupo formado pelo arcebispo, tinha pensado em criar um diário de seus passos. Em seguida recorreu a técnica que usava desde sempre: começou escrevendo em pedaços de papelão das caixas de camisas vazias, depois reuniria esse material e poderia datilografar em iídiche. Conseguiu elaborar vários cartões, mas não o finalizava. Havia uma insuficiência da qual a literatura parecia não dar conta: "Seu bloqueio era moral, não era linguístico: estava errado fazer da tragédia de sua filha objeto de criação literária, nada podia estar mais errado".${ }^{30}$ Ele destruiu os cartões e desistiu do iídiche. Ofendeu a língua que até ali era a expressão da sua arte, porque por ela teria se afastado da filha. Jurou que não queria mais essa língua de "fracos", referindo-se de maneira cruel à acusação de que os judeus teriam se deixado matar.

Giorgio Agamben, na obra O que resta de Auschwitz: o arquivo e a testemunha ${ }^{31}$, recupera o horror dos campos de concentração nazista para analisar a dificuldade do testemunho, a sua talvez impossibilidade ética e ao mesmo tempo o exemplo dos que o fizeram. Ele recupera as análises e a narrativa de Primo Levi para discutir a figura da testemunha. De acordo com as considerações de Agamben, a aporia de Auschwitz é justamente um excesso de realidade: “O que aconteceu nos campos aparece aos sobreviventes como a única coisa verdadeira e, como tal, absolutamente inesquecível; por outro lado, tal verdade é, exatamente na mesma medida inimaginável, ou seja, irredutível aos elementos reais que a constituem. Trata-se de fatos tão reais que,

\footnotetext{
${ }^{28}$ Idem, ibidem, p. 80.

${ }^{29}$ Cf. idem, ibidem, p. 84.

${ }^{30}$ Idem, ibidem, p. 133.

${ }^{31}$ AGAMBEN, Giorgio. O que resta de Auschwitz: o arquivo e a testemunha (Homo Sacer III). São Paulo: Boitempo, 2008.
} 
comparativamente, nada é mais verdadeiro; uma realidade que excede necessariamente os seus elementos factuais". ${ }^{32}$

Ainda assim, os testemunhos continuaram sendo feitos e havia algo "essencial" nos relatos, que eram o que Agamben chama de lacunas. Não era uma questão de ouvir os detalhes das experiências dos campos, mas abrir-se a escuta dessas ausências, dos hiatos. Patrizia Violi é bastante crítica às discussões que se seguiram sobre a impossibilidade ou não dos testemunhos após a Shoah. Segundo ela, muitos se excederam em questões abstratas e acabavam por reforçar um silenciamento dos sobreviventes que, lembremos, são também vítimas.

Não está em jogo somente uma impossibilidade psicológica da vítima, mas um bem mais radical interdito existencial. De Adorno (1966) a Lyotard (1979), até Agamben (1995,1998), a filosofia questionou muito sobre este tema, refletindo sobre uma estética de impossibilidade da representação e do testemunho. É legítimo, todavia, interrogar sobre o porquê, depois de tudo, as vítimas não poderiam, ou não deveriam, narrar o trauma. Olhando de perto, uma posição como essa parece pressupor quase uma sanção implícita para com os sobreviventes, quase uma responsabilização pelo próprio fato de terem sobrevivido. Permanece uma hipótese de que algumas reflexões filosóficas sobre este tema pequem do mesmo excesso de abstração que caracteriza a ideia de crise de representação. Apesar de todas as dificuldades que o ato de testemunhar comporta, as vítimas continuaram a fazê-lo.33

Confrontando-se com as dificuldades desse testemunho, mas sem desistir de fazê-lo, $K$. recupera uma outra língua, também parte de suas raízes, o hebraico, e decide, então, escrever às netas que moravam em Israel para contar a elas o que tinha acontecido. Apropria-se de um novo meio, outros destinatários e uma nova língua, mas não abdica dessa possibilidade de diálogo. O protagonista do romance, nesse país doente, resiste e busca uma re-existência em possibilidades outras de memória e história para a filha desaparecida: "Naquela mesma noite, K. escreveu sua primeira carta à neta em Eretz Israel, em hebraico impecável, como ele aprendera de criança no heder. Assim, não era mais o escritor renomado a fazer literatura com a desgraça da filha; era o avô legando para os netos o registro de uma tragédia familiar" ${ }^{34}$

Por outro lado, quando as autoridades decidem falar, o protagonista deseja que elas não tivessem se pronunciado. O emaranhado de mentiras dos gestos oficiais distorce a perspectiva de uma sociedade lúcida, em que o normal seria exatamente que os cidadãos pudessem confiar nas informações que lhes seriam dadas. Por isso, ao se pronunciar, o regime parece ferir tanto ou mais do que em silêncio. Um dos episódios citados é quando o ministro

\footnotetext{
${ }^{32}$ Idem, ibidem, p. 20.

33 VIOLI, Patrizia, op. cit., p. 52. Tradução minha do original: “Non è qui in gioco soltato un'impossibilità psicologica della vittima, ma un ben più radicale interdetto esistenziale. Da Adorno (1966) a Lyotard (1979), fino ad Agamben (1995,1998), la filosofia si è molto interrogata su questo tema, riflettendo su un'estetica dell'irrapresentabile e sull'impossibilità della testimonianza. È leggitimo tuttavia interrogarsi sul perché, dopotutto, le vittime non potrebbero, o non dovrebbero, raccontare. Rimane il sospetto che alcune riflessioni filosofiche su questa tema pecchino della medesima eccesiva astrattezza che caratterizza l'idea di crisi della rappresentazione: nonostante tutte le difficoltà che l'atto di testimonianza comporta, di fatto le vittime hanno continuato a testimoniare".

${ }^{34}$ KUCINSKI, Bernardo, op. cit., p. 134.
} 
da Justiça prometera uma resposta à lista dos desaparecidos divulgada na imprensa pelo arcebispo. Naquele dia, K. teve a impressão de que a Terra pararia de girar por alguns segundos. Mas já no início do pronunciamento dá-se conta de que tinha sido enganado. $\mathrm{O}$ nome da filha deveria estar no início da lista (Ana), mas é citada mais tarde, junto com o marido, dizendo que sobre eles o governo não possui nenhum registro. “Em vez de 22 explicações, 27 mentiras". ${ }^{35}$

Em outro momento, K. foi chamado ao Tribunal de Justiça Militar para depor contra um sargento que teria recebido dinheiro em troca da possibilidade de informações sobre Ana Rosa. Meses atrás ele tinha sido abordado pelo militar que lhe ofereceu a possibilidade de receber uma carta escrita pela filha. K. nem sabia explicar por que tinha aceitado a oferta, mas sentia que não conseguia deixar de fazê-lo. De qualquer forma, logo no início do julgamento, o protagonista percebe que a situação fora montada como reprimenda ao sargento que teria envergonhado a instituição, uma vez que a história da extorsão apareceu nos jornais. K. tinha alertado outros familiares sobre a armadilha, e um jornalista que participava das reuniões fez a denúncia na imprensa. Efetivamente, “K. não está interessado no destino do impostor. Ele veio para perguntar sobre a filha nesse contato formal com a Justiça, o primeiro e único. Afinal, seu sumiço era a razão de tudo. Por isso insistira com o jovem advogado para acompanhá-lo ao tribunal militar. Ele saberia como pedir, no momento próprio, um esclarecimento sobre o sumiço da filha. Mas o estagiário falhou de novo. Não veio". ${ }^{36}$

A sessão termina com a condenação do sargento que ficará preso um ano e perderá a patente militar por ter mentido ofendendo as Forças Armadas. Quando questionados sobre Ana Rosa, os juízes militares pedem então que conste nos autos que nenhum civil esteve detido nas instalações militares, conforme confissão do réu. Durante o julgamento, K. se lembra das palavras de um advogado conhecido que seguia tentando lutar por direitos humanos no país: "Vivemos um paradoxo - ele lembra o grande advogado dizer - admitem que têm motivos políticos para prender, mas não reconhecem que prenderam". ${ }^{37}$

Ainda nesse capítulo - "Os extorsionários" - o protagonista faz uma reflexão sobre a potência e a articulação do regime, uma vez que ele já tinha sido abordado outras vezes por diferentes informantes que prometiam notícias da filha, o que depois não resultava em nada. Ele questiona a própria ingenuidade porque sabe de pessoas muito mais ricas e influentes que também não conseguiram reaver os familiares, nem seus corpos. Por outro lado, ele imagina o quão poderoso era esse sistema de apagamento das existências. Nesse trecho, o narrador interfere e acrescenta às reflexões de K.: “Ele não podia saber que quarenta anos depois esse muro ainda estaria em pé, intoca$\mathrm{do}^{\prime \prime}{ }^{38} \mathrm{O}$ livro então, dedicará os três últimos capítulos a contar a saga desse pai, já em um momento posterior à queda oficial do regime militar.

\footnotetext{
${ }^{35}$ Idem, ibidem, p. 70.

${ }^{36}$ Idem, ibidem, p. 143.

${ }^{37}$ Idem, ibidem, p. 144

${ }^{38}$ Idem, ibidem, p. 142.
} 
O primeiro deles, "As ruas e os nomes", aborda de maneira exemplar a marginalidade da memória das vítimas da ditadura no patrimônio coletivo brasileiro. Segundo Violi, “o patrimônio traumático é o resultado de um processo não apenas de reconstrução cultural no sentido de um determinado evento, mas também da atribuição de valor que se dá aquele evento" ${ }^{39}$ No romance, o protagonista é convidado por um vereador "da esquerda" para uma cerimônia de nomeação de 47 ruas de um bairro novo da cidade com os nomes dos desaparecidos políticos. Apesar do discurso sobre uma "nova ordem de valores" que o político tentou enfatizar, K. se sentiu ofendido pelo nome de Vila Redentora que deram ao bairro. Era desse jeito que os militares chamavam o golpe. Depois, tentou se conformar, porque, de alguma forma, um reconhecimento aos mortos e desaparecidos estava sendo feito pelas autoridades. Essa satisfação, porém, dura menos que o tempo da viagem de volta para casa. No caminho, ele se depara com avenidas, pontes e viadutos em homenagem a ditadores e torturadores:

Ao se aproximar de São Paulo, o ônibus passou debaixo de uma ponte que trazia a placa Viaduto General Milton Tavares. De novo esse criminoso, K. passara muitas vezes debaixo daquela ponte sem prestar atenção ao nome. Centenas de pessoas passam por aqui todos os dias, jovens, crianças e leem esse nome na placa, e podem pensar que é um herói. Devem pensar isso. Agora ele entendia por que as placas com os nomes dos desaparecidos foram postas num fim do mundo. ${ }^{40}$

O reconhecimento periférico, quase escondido no fim do mundo, conforme nos conta o narrador, apresenta as diferenças de valorização dos traumas que cita Violi. Para a estudiosa, quando o trauma não obtém um reconhecimento e um valor compartilhado na sociedade, as vítimas acabam tendo suas memórias marginalizadas, na maioria das vezes empurradas para uma dimensão individual, solitária. Tal qual os graves sintomas da doença de Alzheimer que vai corroendo as possibilidades de integração social do paciente, os sobreviventes de um trauma que é a todo tempo apagado ou silenciado acabam por se ver desvinculados da sociedade a qual pertencem. No capítulo seguinte, "Sobreviventes, uma reflexão", o narrador tenta justamente pensar sobre esse confinamento para o qual as vítimas e os familiares se veem impelidos.

A primeira consideração proposta é que, apesar das particularidades de cada experiência, no geral, nenhum sobrevivente se sente confortável para elencar as perdas que sofreu. A culpa é um fardo que todos carregam, de maneiras e intensidades diferentes. O sentimento de dúvida sobre se poderia ou não ter feito algo ou reagido de outro jeito vai e volta como fantasmas. Essa culpa pela sobrevivência é comparada a uma análise que Milan Kundera faz da obra O processo, de Kafka, quando Joseph K. vasculha os detalhes de seu passado em busca do erro que teria cometido e pelo qual estava sendo julgado. Na análise, Kundera fala em totalitarismo familiar porque lê na obra de

\footnotetext{
${ }^{39}$ VIOLI, Patrizia, op. cit., p. 62. Tradução minha do original: “Il patrimonio traumatico è l'esito di un processo non solo di ricostruzione culturale del senso di un dato evento, ma anche dell'attribuzione di un valore a quell'evento".

${ }^{40}$ KUCINSKI, Bernardo, op. cit., p. 159.
} 
Kafka a opressão que o filho sente diante do julgamento do pai. O narrador de K., porém, apropria-se do termo e o transforma em "totalitarismo institucional", porque para ele as autoridades institucionais brasileiras é que continuam a infringir essa violência aos sobreviventes da ditadura militar. Porque sem verdade, sem justiça e sem memória, não há como compartilhar o patrimônio traumático dessa experiência e conectar-se novamente com a sociedade da qual faz parte: “O 'totalitarismo individual' exige que a culpa, alimentada pela dúvida e opacidade dos segredos, e reforçada pelo recebimento das indenizações, permaneça dentro de cada sobrevivente como drama pessoal e familiar, e não como a tragédia coletiva que foi e continua sendo, meio século depois". ${ }^{41}$

A última cena narrada sobre a saga de K. é o capítulo “No Barro Bran$\mathrm{CO}^{\prime \prime}$. Um dos antigos fregueses da loja avisou que presos políticos foram enviados ao quartel do Barro Branco. Alguns deles poderiam ter visto a filha ou o genro, ou ter notícia sobre eles. O narrador descreve as primeiras lembranças de K. sobre o quartel. Ele conhecia bem o lugar, passou muitas vezes em frente àquela fachada com a charrete, quando ainda trabalhava como mascate. No mesmo trecho, a memória de K. viaja até a Polônia, sua terra natal, que também o levou para a cadeia. Na época, ele aprendeu o quanto chocolates e cigarros eram de suma importância, e foi isso que decidiu levar aos prisioneiros que aceitassem vê-lo. Ao entrar no quartel, o pai de Ana Rosa estava tonto, fraco e suava muito. Ele consegue chegar no pavilhão somente pela ajuda de um sargento. Está ali para uma "prestação de contas; um ciclo de vida que se completava, o fim tocando o início e no meio nada". ${ }^{42}$

As descrições do narrador nos mostram a imagem desse velho pai cansado da busca. Ao mesmo tempo, esse retorno ao início citado se dá, especialmente, pela voz e a linguagem. K. se senta entre os presos e conta a história do desaparecimento da filha, como já tinha feito inúmeras vezes. Mas agora, em alguns momentos, ele recuperava o iídiche, a língua contra a qual praguejou, a qual ele culpou pela distração, mas que ao fim é sua língua literária, afetiva, e com ela também recuperava um pouco do sotaque que tinha nos primeiros dias de imigrante no Brasil. Parecia fazer um acordo de paz consigo mesmo. Quando os presos confirmaram a morte de Ana Rosa, o velho pai se curvou para frente, chorou muito e caiu. Por fim, na última descrição de K., ele se encontra deitado, olhando os presos a seu redor, e por trás dele a janela que mostrava um sol e prometia liberdade, mas que parecia não mais pertencer a esse pai. Ele agora estava "muito cansado, mas em paz". ${ }^{43}$

\section{Um manifesto para o país}

O romance de Bernardo Kucinski apresenta várias vozes narrativas que permeiam a obra (os militantes, os militares, funcionários da casa de tortura, a amante do torturador, os professores universitários e outros), mas neste artigo escolhi fazer uma leitura focada na saga do protagonista em busca da filha desaparecida. Na análise, a partir da metáfora proposta pelo próprio au-

${ }^{41}$ Idem, ibidem, p. 163.

42 Idem, ibidem, p. 168.

${ }^{43}$ Idem, ibidem, p. 169 
tor de um país que sofre de mal de Alzheimer, propus um recorte que pudesse diagnosticar no romance alguns dos sintomas dessa nação e sociedade doentes. Além disso, procurei acentuar o próprio gesto literário de Kucinski e a insistente resistência de seu protagonista como respostas a esses mecanismos patológicos.

Se, como nos propõe Violi, refletir sobre a memória do passado é prefigurar uma imagem do futuro, entendo o romance de Bernardo Kucinski como um alerta sobre os graves sintomas e as consequências problemáticas em insistir nesse cruel aparato de não memória, de ignorar a possibilidade de uma justiça de transição e tentar conceber a ditadura militar como uma página virada quando o "totalitarismo institucional" ainda se faz preponderante. Se a primeira paciente de Alois Alzheimer morreu isolada e apática, como nos conta o prontuário histórico, imagino o gesto literário de Bernardo Kucinski como um movimento não só para completar seu luto, homenagear a história da irmã ou construir uma possibilidade de restituição de sua memória, mas como um manifesto para o país. É uma reflexão sobre a degeneração cognitiva de nossa sociedade que, por renegar a memória, está deixando para trás a capacidade de permanecer lúcida.

Artigo recebido em 25 de fevereiro de 2021. Aprovado em 20 de março de 2021. 